\title{
Evaluation of Crystalline Penicillin Use in Pediatrics Ward of Jimma University Specialized Hospital, South West Ethiopia
}

\section{Jafer Siraj ${ }^{1}$ and Seid Mussa Ahmed ${ }^{2 *}$}

${ }^{1}$ Jimma University, Jimma University Specialized Hospital, 378, Jimma, Ethiopia

${ }^{2}$ Jimma University, College of Public Health and Medical Sciences, Department of Pharmacy, 378, Jimma, Ethiopia

\begin{abstract}
Background: Crystalline penicillin has been used for chemotherapy of bacterial infections for pediatrics over the years. However, not much is known about the appropriateness of clinical indication, dosages administered, frequency of administration, duration, drug interactions, contra-indications and outcome of therapy in Jimma University Specialized Hospital (JUSH) Pediatrics Ward.
\end{abstract}

Objective: The present study was undertaken to evaluate crystalline penicillin use and its appropriateness in pediatrics ward of JUSH, South West Ethiopia.

Methods: Retrospective cross sectional study of medication records of hospitalized pediatric patients who received crystalline penicillin from January 1 to December 31, 2012 at pediatrics ward of JUSH was done from February 4 to 17, 2013 to assess utilization pattern of crystalline penicillin.

Results: A total 183 hospitalized pediatrics patient records were included in the study. In all cases, the indication to use, frequency of administration, contra-indications and drug interactions of crystalline penicillin were according to the national standard treatment guideline of Ethiopia for General Hospitals, and World Health Organization Guidelines for the management of common illnesses in children in areas with limited resources. All the $183(100 \%)$ cases were consistent with guidelines for indications, contra-indications and dose frequency to use the drug. Moreover, one hundred and eighty one $(98.9 \%)$ of the cases were in accordance with the guidelines for contraindications. However, only $149(81.42 \%), 153(83.6 \%)$ and $168(91.80 \%)$ of the cases were in accordance with the guidelines to use the drug with regard to dose, duration and outcome of treatments, respectively.

Conclusion and recommendation: Consistency of prescribers to the national standard treatment guideline was found to be promising. To improve rational use and prevent the development of resistance, intensification of short term trainings and antibiotic control systems are some of the possible solutions the hospital has to do. In addition, prescribers should regularly check completeness of patient cards.

Keywords: Drug use evaluation; Pediatrics; Patient cards; Crystalline penicillin; Standard treatment Guidelines; World Health Organization (WHO); Jimma university specialized hospital

Abbreviations: ADRS: Adverse Drug Reactions; CAF: Chloramphenicol; CAP: Community-Acquired Pneumonia; CAMRSA: Community-Associated Methicillin-Resistant Staphylococcus Aureus; CNS: Central Nervous System; C. Pen: Crystalline Penicillin; DUE: Drug Use Evaluation; GPs: General Practitioners; IM: Intramuscular; IU: International Unit; IV: Intravascular; JUSH: Jimma University Specialized Hospital; PO: Per Oral; Q: Every; QID: Four Times a Day; SPSS: Statistical Package for the Social Sciences; STG: Standard Treatment Guideline; TAT: Tetanus Antitoxin; TID: Three Times a Day; URTIs: Upper Respiratory Tract Infections; WHO: World Health Organization

\section{Introduction}

Drug Use Evaluation (DUE) is a system of ongoing, systematic criteria based evaluation of drug use that will help ensure that medicines are used appropriately at the individual patient level [1].

DUE may be applied to a drug, therapeutic class, disease state or condition, a drug use process or outcomes [2]. DUE can assess the actual process of medication prescribing, administration, or dispensing. It involves a comprehensive review of patients' prescription and medication data before, during and after dispensing in order to assure appropriate therapeutic decision making and positive outcome [3]. If properly developed, it not only provides a means of identifying drug use problems but also provides a means to correct the problem and there by contribute to rational drug therapy [4].

The potential inappropriate uses of medicines are becoming a concern worldwide with their increment in quantity and variety. Inappropriate use is associated with health risks to the patient and financial crisis to the health facilities and patients. As a result, numerous articles, conferences and studies try to address the issue and design strategies to identify, resolve and prevent inappropriate medicine use [5]. The rational use of medicines requires that patients receive medications appropriate to their clinical needs, in doses that meet their own individual requirements, for an adequate period of time and at the lowest cost to them and their community. However, ensuring the rational use of medicines remains a challenge for public health providers and administrators in many countries [6].

Modern medicine has various milestones, but one of the most important is, without doubt, the discovery of effective agents to prevent and treat infections caused by bacteria and other microorganisms. Antibiotics were first used clinically in 1936, starting with sulfonamides and followed in the 1940s by penicillin and streptomycin [7]. Thereafter,

*Corresponding author: Seid Mussa Ahmed, Department of Pharmacy, Jimma University, Jimma University Specialized Hospital, College of Public Health and Medical Sciences, 378, Jimma, Ethiopia, Tel: +251911820125; E-mail: seid.mussa@ju.edu.et, plss1176@gmail.com

Received September 25, 2013; Accepted October 14, 2013; Published October 21, 2013

Citation: Siraj J, Ahmed SM (2013) Evaluation of Crystalline Penicillin Use in Pediatrics Ward of Jimma University Specialized Hospital, South West Ethiopia. Clin Exp Pharmacol 3: 135. doi:10.4172/2161-1459.1000135

Copyright: (c) 2013 Siraj J, et al. This is an open-access article distributed under the terms of the Creative Commons Attribution License, which permits unrestricted use, distribution, and reproduction in any medium, provided the original author and source are credited. 
new molecules were discovered on a regular basis and the golden age of antimicrobial chemotherapy was under way. Unfortunately, along with the introduction of new molecules, a foreseeable problem emerged: resistance of microorganisms to available antibiotics. Antibiotic resistance is a major concern globally. Antibiotic consumption increases the likelihood for an individual to develop bacterial resistance [8]. The majority of antibiotic prescribing takes place in primary care and General Practitioners(GPs) have been encouraged to prescribe antibiotics more rationally and to only give antibiotics when necessary [9]. Wide variation in antibiotic prescribing practices has been reported globally. Inappropriate use of antimicrobials, overuse of injections when oral formulations would be more appropriate, the use of too many medicines per patient (polypharmacy), failure to prescribe in accordance with clinical guidelines, inappropriate selfmedication (often of prescription only medicines) are some of the forms of irrational prescribing as described by numerous studies from developed and developing countries [10,11].

Respiratory tract infections are among the most frequently encountered clinical conditions and Upper Respiratory Tract Infections (URTIs) are one of the most common reasons for pediatrics consultations in primary health care $[12,13]$. Children in developing countries suffer an annual average of six URTIs [10], with a high incidence in the first 7 years of life, which are termed the "catarrhal" stage [12]. These infections impose a burden on the health care system and are a major reason for absenteeism from school and work by children and parents respectively [13].

Although antibiotics are targeted to kill or inhibit the growth of bacteria and have no effect on viral agents [14], it is often inappropriately used to treat viral infections, such as most of Upper Respiratory Tract Infections (URTIs). Problems associated with the overuse of antibiotics include development of antibacterial resistance, increasing the burden of chronic diseases, raising costs of health services, and the development of side effects (e.g., adverse gastrointestinal effects). In most developing countries governments spend about $20-50 \%$ of their national budget on drugs and medical sundries [15]. This makes the financial impact of pharmaceuticals on their economies to be substantial. Governments are thus concerned about the rational use of these drugs. Furthermore, the World Health Organization Policy Perspective on Medicine also indicates that even when drugs are made available, more than fifty percent are prescribed, dispensed or sold inappropriately while $50 \%$ of patients fail to take the medicines correctly resulting in harmful consequences [11]. One of the major consequences of such inappropriate use of antibiotics is the development of resistance strains of the hitherto susceptible organism. Inappropriate treatment could also lead to the ultimate death of the patient $[16,17]$.

There are certain unique set of challenges to the prescribers as to the use of medicines in infants and children is concerned. It is obvious that the actions, effectiveness and safety of medicines are influenced significantly by physiological variances between children and adults, including the ontogeny of organ maturity and body composition. However, most pharmacokinetic and pharmacodynamic studies provide little, if any, information on drug action in infants and children, because children are excluded in studies and usually conducted in adults [16]. The 'Better Medicine for Children' slogan of 2007, World Health Assembly, recognized the need for research and development on medicines for children including better dosage forms, better evidence and better information about how to ensure that medicines for treating the common childhood diseases are given at the right dose for children of all ages [17].
The increased prevalence of known resistant organisms and the emergence of newly resistant organisms have resulted in delays in effective therapy and the length of hospitalization and have led to increased costs for patients. When considering this, the logical first step is to evaluate the suitability of antibiotic usage. Antibiotic use evaluation is a basic measure for evaluating the appropriate usage of antimicrobial agents [18]. An improvement of resistances can be achieved as documented in Scandinavia by temporary reduction of the use of the respective classes of antibiotics [19].

Irrational drug use in paediatrics could be due to lack of appropriate information on drugs, or treatment protocols or therapeutic guidelines for common clinical conditions. Furthermore, lack or shortage of drugs also predisposes to misuse of drugs. So far no study has been conducted to assess the crystalline penicillin utilisation pattern in paediatrics ward of Jimma University Specialized Hospital. So, drug use evaluation for crystalline penicillin is important for this hospital to minimize over and inappropriate use of antibiotics. Thus, the aim of the present study was to evaluate the utilisation pattern of crystalline penicillin in paediatrics ward of the teaching and referral hospital.

To the knowledge of the investigators, there are no published studies dealing with evaluation of crystalline penicillin use even not in pediatrics age group but also in other age group like adults in Ethiopia and hence little is known about the drug use evaluation of other drugs in JUSH. The outcome of this study will provide useful information regarding crystalline penicillin use and the level of appropriateness among pediatric patients in the hospital. Moreover, the study will also generate tangible data about crystalline penicillin consumption in pediatrics ward for appropriate intervention and planning thereafter. It also serves as baseline information for further assessment of drug related problems in this group of patients.

\section{Subjects and Methods}

\section{Study area and period}

The study was conducted in Jimma University Specialized Hospital (JUSH) pediatrics ward which is found in Jimma Town, South-West Ethiopia from February 4 to 17, 2013.

Currently JUSH is the only teaching and referral hospital in the southwestern part of the country. It had a bed capacity of 450 beds and a total of more than 750 staff of both supportive and professional. It provides services for approximately 9000 inpatient and 80000 outpatient attendances per year coming to the hospital from the catchment population of about 15 million people [20].

\section{Study design}

A retrospective cross sectional study was conducted by reviewing the medical records (cards) of pediatric patients for whom crystalline penicillin was prescribed (i.e., patient cards containing crystalline penicillin). The card numbers of patients were registered from patient discharge book based on indication for crystalline penicillin use. Those card numbers were used to help identify patient cards prescribed with crystalline penicillin from other cards. And these patient cards were closely scrutinized for fulfillment of necessary information.

\section{Population}

The source of populations was a total of one year pediatric patients cards beginning from January 1 to December 31, 2012. The study population was all pediatric patients' cards containing crystalline penicillin and fulfill necessary information from January 1 to December 31, 2012. 
In this study the inclusion criteria were cards containing information about hospitalized pediatric patients who were put on crystalline penicillin and the exclusion Criteria were Pediatric patients' cards that did not fulfill necessary information for crystalline penicillin like indication for use, weight of the patient (to calculate the dose of crystalline penicillin), etc.

\section{Sample size and sampling technique}

No sample size calculation and sampling technique was needed since the study included all pediatric patients' cards containing crystalline penicillin at JUSH pediatrics ward from January 1 to December 31, 2012. The study has included those patients' cards that only fulfill the inclusion criteria.

\section{Data collection}

Because there is no standard treatment guideline for referral hospitals, drug use evaluation criteria with thresholds were set based on the national STG of Ethiopia for General Hospitals, WHO guide for drug use evaluation and WHO Guidelines for the management of common illnesses in children in areas with limited resources [4,21,22].
In this study seven criteria were set namely indication for use, dose, dose frequency, duration of treatment, contra-indications, drug interactions and outcome of treatment were used to evaluate crystalline penicillin use. For each criterion a threshold limit was set to measure the extent of practitioner's adherence to the national STG (Table 1).

Data collection format was developed according to WHO recommendation. The card numbers of patients were registered from patient discharge book in pediatric ward based on indication for crystalline penicillin use and the data were collected from the patient chart and analyzed for fulfillment of necessary information. The formats contained patient information (presence of sex, age, weight, card number, etc.), clinical information and pattern of crystalline penicillin use. The data were collected by three trained nurses working in the pediatrics ward of JUSH. Data collectors were closely assisted and supervised by the investigators. Each case from the patient medication records was evaluated against the national STG of Ethiopia for General Hospitals, and WHO Guidelines for the management of common illnesses in children in areas with limited resources for set criteria for crystalline penicillin therapy (Table 2).

\begin{tabular}{|c|c|c|}
\hline Indicator & Criteria & Threshold (\%) \\
\hline Dose and dose frequency & $\begin{array}{l}\text { Severe Pneumonia } \\
\text { Pyogenic meningitis (Meningococcal meningitis and Pneumococcal meningitis) } \\
\text { Generalized Neonatal tetanus } \\
\text { Congenital syphilis } \\
\text { Neonatal sepsis } \\
\text { Cellulites } \\
\text { Erysipelas } \\
\text { Endocarditis } \\
\text { Bacteremia: } 25,000 \text { to } 50,000 \text { units/kg/dose IV infusion over } 30 \text { minutes, or IM } \\
\text { Severe Pneumonia: } 50,000 \text { units/kg/24 hours IV QID } \\
\text { Meningococcal meningitis: } 250,000 \text { units/kg/dose IV infusion over } 30 \text { minutes, or IM every } 4 \text { hour } \\
\text { Pneumococcal meningitis: } 250,000 \text { units/kg/dose IV infusion over } 30 \text { minutes, or IM every } 4 \text { hour } \\
\text { Neonatal sepsis: } 50,000 \text { IU } / \mathrm{kg} / 24 \mathrm{hours} \text { IV QID } \\
\text { Neonatal tetanus: } 50,000 \text { IU } / \mathrm{kg} / 24 \mathrm{hours} \text { IV QID } \\
\text { Cellulites: } 50,000 \text { IU/kg/24hours IV } 4 \text { hourly } \\
\text { Erysipelas: } 50,000 \text { IU/kg/24hours IV } \\
\text { Prevention of Bacterial Endocarditis: } 50,000 \text { IU } / \mathrm{kg} \text { intravenously or intramuscularly } 30 \text { to } 60 \text { minutes before the } \\
\text { procedure and, } 1 \text { million IU ( } 25,000 \text { IU/kg for children) six hours later } \\
\text { Gonococcus infection (only with proven penicillin-susceptible isolate): } 100,000 \text { units/kg/dose IV infusion over } 30 \\
\text { minutes, or IM } \\
\text { Congenital syphilis: } 50,000 \text { units/kg/dose IV over } 30 \text { minutes, given Q } 12 \text { hours during the first } 7 \text { days of life }\end{array}$ & 95 \\
\hline Duration & $\begin{array}{l}\text { Congenital syphilis: } 10-14 \text { days } \\
\text { Severe Pneumonia: } 3 \text { days } \\
\text { Meningococcal meningitis: } 10 \text { days } \\
\text { Pneumococcal meningitis: } 7 \text { days } \\
\text { Neonatal sepsis: } 10 \text { days } \\
\text { Neonatal tetanus: } 10 \text { days } \\
\text { Cellulites: } 10 \text { days } \\
\text { Erysipelas: until the fever subside } \\
\text { Endocarditis: } 2-6 \text { weeks }\end{array}$ & 90 \\
\hline Contra-indications & Penicillin hypersensitivity reaction; avoid intrathecal route & 100 \\
\hline Drug interactions & $\begin{array}{l}\text { Methotrexate, } \\
\text { - } \quad \text { Probenecid (decrease renal tubular secretion of the penicillin's), } \\
\text { set) }\end{array}$ & 90 \\
\hline Outcome & 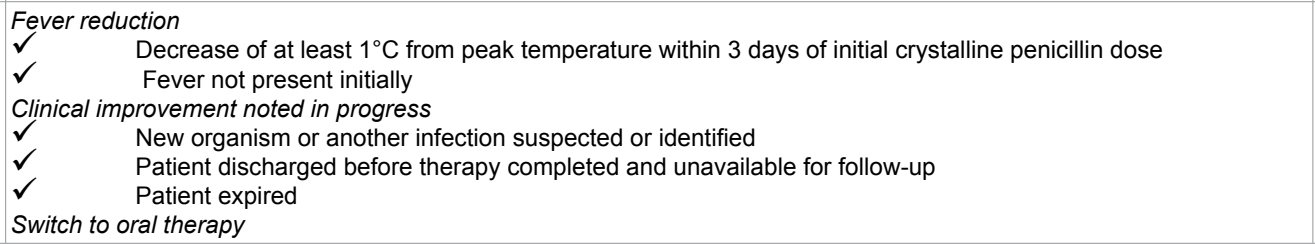 & 95 \\
\hline
\end{tabular}

Table 1: Drug use evaluation criteria for crystalline penicillin. 


\section{Data processing and analysis}

The collected data were coded and entered to SPSS for windows version 16.0 statistical software. The data were processed and analyzed by using the set criteria for drug use evaluation with thresholds against the national STG of Ethiopia for General Hospitals, and WHO Guidelines for the management of common illnesses in children in areas with limited resources. In this study the seven set criterion with the threshold limits were used to evaluate crystalline penicillin use.

\section{Ethical consideration}

The study was approved by Jimma University, College of Public Health and Medical Sciences Research and Ethics Review Committee. Permission letter was then secured from Medical Director Office of JUSH. Moreover, permission was sought from heads of pediatrics department and card room/medical records room of the hospital. All the responsible officials were informed about purpose and aim of the study and permission was obtained. The confidentiality of data collected was maintained. Name and address of patient and prescriber was omitted from the data collection format. Ethical issues were considered during data collection in order not to disclose patient and professional information to persons outside the research.

\section{Limitation of the study}

The possible limitations of the study were incomplete patient charts; all necessary information was not recorded (age, weight, duration of therapy, frequency, etc.) on the patient cards. Due to this evaluation of all the prescribed crystalline penicillin was not determined and some patient cards prescribed with crystalline penicillin were rejected from the study. Consequently the sample size became inevitably reduced. Moreover, since there is no standard treatment guideline for referral hospitals in Ethiopia, a combination of the national STG of Ethiopia for General Hospitals and WHO Guidelines for the management of common illnesses in children in areas with limited resources was used as criteria for evaluation and this might have effect on the evaluation/ analysis.

\section{Results}

Out of 324 patients' cards only 183 cards were found to have complete information for the intended purpose of crystalline penicillin. Among the 183 patients, 87 (47.54\%) were female and 96 (52.46\%) were male. The number of female patients was lower as compared to their male counter parts. Fifty nine patients $(32.24 \%)$ were in the age group of 1 to 12 months. The majority of the patient age group was between 13 to 60 months which represents $72(39.34 \%)$ patients. The rest $29(15.85 \%)$ and $23(12.57 \%)$ of the patient were found between 61 to 120 and 121 to 192 months respectively (Table 3 ).

In line with the indication recommended, crystalline Penicillin was used $100 \%$ as per the guideline for the conditions listed (Table 4 ). The morbidity profile for the patients on crystalline penicillin is shown in Table 4. Severe pneumonia was the most common indication for which crystalline penicillin was prescribed constituting 114 cases (62.29\%).

There were $26(14.21 \%)$ patients treated with antibiotics before indication of crystalline penicillin. Out of these cases, 9 (4.92\%) were treated with cotrimoxazole followed by ampicillin+gentamicin $5(2.73 \%)$, CAF+cloxacillin 4 (2.19\%), cloxacillin+gentamicin $3(1.64 \%)$. The rest 3, 2 and 1 case were treated with amoxicillin, ceftriaxone, and ceftriaxone+gentamicin, respectively. The reason why the antibiotics were stopped was not specified or recorded on patient cards. So, the rationale of converting or shifting this antibiotic to crystalline penicillin is unknown.

The dose of crystalline penicillin was not calculated as per the weights of the pediatric patient as observed in some pediatric records. Only $34(18.6 \%)$ and $30(16.4 \%)$ of the patients had received inappropriate doses and durations, respectively especially in the treatment of pyogenic meningitis and generalized tetanus. Generally, the majority of dosage administered was between 250,000-495,000 IU which constitutes 83 (45.36\%) patients (Table 5).

Duration of crystalline penicillin use varied for the various indications as expected and even for the same indication there were variations. For example out of the 114 cases of severe pneumonia 22 (19.30\%) have been treated for one day and 72 (63.16\%) have been treated for 2-5 days duration of treatment. On the other hand, most of the cases of pyogenic meningitis and generalized tetanus were treated for 6-10 days and $>15$ days, respectively.

Generally, the minimum duration of treatment was one day and 32

\begin{tabular}{|c|c|c|c|c|}
\hline Disease condition & Drugs recommended & Dosage & Frequency of Administration & Duration \\
\hline \multirow[b]{4}{*}{ Pyogenic meningitis } & \multirow{2}{*}{ Crystalline penicillin plus } & $50,000 \mathrm{IU} / \mathrm{kg}$ IV followed by & single dose & \multirow{4}{*}{$10-15$ days } \\
\hline & & $250,000 \mathrm{IU} / \mathrm{kg} / 24$ hours IV & divided in 8 doses (Q 3 hourly) & \\
\hline & \multirow{2}{*}{ Chloramphenicol, } & $50 \mathrm{mg} / \mathrm{kg}$ IV followed by & single dose & \\
\hline & & $100 \mathrm{mg} / \mathrm{kg} / 24$ hours & $\begin{array}{l}\text { divided in to four doses (Q } 6 \\
\text { hourly) }\end{array}$ & \\
\hline Severe Pneumonia & Benzyl penicillin, & 50,000 units/kg/24hrs IM OR IV & QID & For at least 3 days \\
\hline \multirow{2}{*}{ Neonatal sepsis } & Penicillin G Sodium Crystalline Plus & $50,000 \mathrm{IU} / \mathrm{kg}$ & QID & \multirow{2}{*}{ For 10 days } \\
\hline & Gentamicin & 5 mg/kg /day IM & TID & \\
\hline \multirow{3}{*}{ Neonatal tetanus } & Tetanus Immune Globulin (TIG), Plus & 500-3000 IU IM should be given & - & - \\
\hline & Penicillin G Sodium Crystalline, Plus & $50,000 \mathrm{lU} / \mathrm{kg} / 24 \mathrm{hrs}$ & QID & For ten days \\
\hline & Chlorpromazine, & $1.6 \mathrm{mg} / \mathrm{kg} / 24$ hours IV/IM & divided in to 4 doses & - \\
\hline Cellulitis & Crystalline Penicillin & 50 million units/kg IV & 4 hourly & 10 days \\
\hline Erysipelas & Crystalline Penicillin & $50,000 \mathrm{IU} / \mathrm{kg}$ & 4 hourly & Until fever subsides \\
\hline \multirow{2}{*}{ Syphilis } & Crystalline penicillin $\mathrm{G}$ followed by & 50,000 units $/ \mathrm{kg}$ IV & every 4 hours & For $10-14$ days \\
\hline & $\begin{array}{l}\text { Benzathine Penicillin at the completion of IV } \\
\text { therapy }\end{array}$ & 50,000 units $/ \mathrm{kg} I \mathrm{M}$ & single dose & - \\
\hline Neonatal Conjunctivitis & Penicillin G Sodium Crystalline, & $50,000 \mathrm{IU} / \mathrm{kg}$ & QID & For 10 days \\
\hline \multirow[b]{2}{*}{ Temporal bone fracture } & Benzyl Penicillin, Plus & $50,000 \mathrm{IU} / \mathrm{kg} \mathrm{IV}$ & every 3 hours & \multirow{2}{*}{ For $10-15$ days } \\
\hline & Gentamicin, & $2-2.5 \mathrm{mg} / \mathrm{kg}$ IM OR IV & TID & \\
\hline
\end{tabular}

Table 2: Protocols for crystalline penicillin use in pediatrics according to STG of Ethiopia. 


\begin{tabular}{|c|c|c|c|c|c|c|}
\hline \multirow{2}{*}{ Age (in months) } & \multicolumn{2}{|c|}{ Male } & \multicolumn{2}{|c|}{ Female } & \multicolumn{2}{|c|}{ Total } \\
\hline & No. & $\%$ & No. & $\%$ & No. & $\%$ \\
\hline $1-12$ & 34 & 18.58 & 25 & 13.66 & 59 & 32.24 \\
\hline $13-60$ & 35 & 19.13 & 37 & 20.22 & 72 & 39.34 \\
\hline $61-120$ & 17 & 9.29 & 12 & 6.56 & 29 & 15.85 \\
\hline $121-192$ & 10 & 5.46 & 13 & 7.10 & 23 & 12.57 \\
\hline Total & 96 & 52.46 & 87 & 47.54 & 183 & 100 \\
\hline
\end{tabular}

Table 3: Age and sex distribution of patients included in the study in pediatrics ward, JUSH, January 1 to December 31, 2012.

\begin{tabular}{|c|c|c|}
\hline Assessment & No. of patients \\
\hline Severe pneumonia & 114 \\
\hline Pyogenic meningitis & 38 \\
\hline Generalized tetanus & 31 \\
\hline Total & 183 & 20.77 \\
\hline
\end{tabular}

Table 4: The most common diseases for which crystalline penicillin was prescribed in pediatrics ward, JUSH, January 1 to December $31,2012$.

\begin{tabular}{|c|c|c|}
\hline Variable & No. of patients \\
\hline Dose & 18 \\
\hline$<245,000$ IU & 83 \\
\hline $250,000-495,000$ IU & 63 \\
\hline $500,000-745,000$ IU & 19 \\
\hline$>750,000 I U$ & 34.84 \\
\hline Duration of therapy (days) & 22 \\
\hline 1 days & 102 \\
\hline $2-5$ days & 27 \\
\hline $6-10$ days & 12 \\
\hline $11-14$ days & 12.02 \\
\hline$>15$ days & 20 \\
\hline Total & 183 \\
\hline
\end{tabular}

Table 5: Crystalline penicillin dosing and dose duration's distribution in pediatrics ward, JUSH, January 1 to December $31,2012$.

days was the maximum number of days. The majority of the patients were treated for $2-5$ days $102(55.74 \%)$. Only a few number of patients $12(6.56 \%)$ were treated between 11-14 days of therapy (Table 5).

When appropriateness of Crystalline Penicillin Utilization was evaluated using WHO Set Criteria in Pediatrics Ward, JUSH against the national STG of Ethiopia for General Hospitals and WHO Guidelines for the management of common illnesses in children in areas with limited resources, among the 183 cases treated nearly twothird $119(65.03 \%)$ of the treatments were found to be appropriate (i.e., treated according to the Ethiopian STG). While the rest 64 (34.97\%) were inappropriate. The causes of inappropriate crystalline penicillin use included incorrect dose of treatment as per the weight of the patient and inappropriate duration of therapy which accounted for 34 cases $(18.58 \%)$ and 30 cases $(16.4 \%)$, respectively.

Usually for severe pneumonia the recommended duration of treatment is not more than three days. But in this study in some cases it was used for 2-5 days and 6-10 days, 10(5.5\%) and greater than 15 days $20(11 \%)$ which is not in line with the recommendations of the guidelines.

The frequency of administration for crystalline penicillin in all patients $183(100 \%)$ was the same. In line with the recommendation of the guidelines, it was administered every four hours for the management of all cases.

Crystalline penicillin was used alone or in combination based on the disease pattern. For example, for the treatment of severe pneumonia it's used alone. In another case (i.e., in pyogenic meningitis and generalized tetanus) crystalline penicillin was used in combination with chloramphenicol and Tetanus Antitoxin (TAT)+chlorpromazine respectively.
Out of total cases (183) about 113(61.75\%) patient were treated with crystalline penicillin alone. And the rest 70 (38.25\%) cases were managed by using combination therapy. About $38(20.94 \%)$ cases of pyogenic meningitis were treated with crystalline penicillin+chloramphenicol and $31(16.94 \%)$ cases of generalized tetanus were managed with crystalline penicillin+TAT+chlorpromazine. One case which was diagnosed with severe pneumonia associated with neonatal sepsis was treated with triple antibiotic therapy comprising crystalline penicillin+ gentamicin+ampicillin.

Clinical improvement was clearly documented for 168 patients (91.80\%), which were identified from conversion of crystalline penicillin to oral antibiotics and discharge summary. Two patients were developing other infectious disease and one patient was expired after conversion of crystalline penicillin to combination of intravenous cloxacillin+chloramphenicol. For 12 cases $(6.56 \%)$, there were no any feedbacks written on the patient's medical records (Table 6).

There were about 88 cases $(48.09 \%)$ switched to other medication especially oral antibiotics. Out of these 84 cases $(45.9 \%)$ had assessment of severe pneumonia and 4 cases $(2.19 \%)$ were due to pyogenic meningitis. Most of the patients were discharged with oral amoxicillin and cotrimoxazole. The number of patients switched to oral amoxicillin were $54(61.36 \%)$, and 27 cases $(30.68 \%)$ were converted to cotrimoxazole oral suspension. Other patients were discharged with chloramphenicol capsule and cephalexin oral suspension which constitutes 3 cases $(3.41 \%)$ and 2 cases $(2.27 \%)$, respectively (Table 7 ). The rest two cases $(2.27 \%)$ were converted to combination of intravenous cloxacillin+chloramphenicol.

There were about 223 drugs co-administered with crystalline penicillin. Among them paracetamol suppository and oral solution 


\begin{tabular}{|c|c|c|c|}
\hline Converted drugs & $\begin{array}{c}\text { Route of } \\
\text { administration }\end{array}$ & No. of patients & Percent \\
\hline Amoxicillin oral suspension & PO & 54 & 61.36 \\
\hline Cotrimoxazole oral suspension & PO & 27 & 30.68 \\
\hline Chloramphenicol capsule & PO & 3 & 3.41 \\
\hline Cephalexin suspension & PO & 2 & 2.27 \\
\hline Cloxacillin + Chloramphenicol & IV & 2 & 2.27 \\
\hline
\end{tabular}

Table 6: Pattern of conversion of crystalline penicillin to other medication in pediatrics ward, JUSH, January 1 to December 31, 2012.

\begin{tabular}{|c|c|c|}
\hline Drugs & Number & Percent \\
\hline Paracetamol & 69 & 30.94 \\
\hline Salbutamol & 68 & 30.49 \\
\hline Intranasal oxygen & 35 & 15.70 \\
\hline Metronidazole & 12 & 5.38 \\
\hline Aminophylline & 8 & 3.59 \\
\hline Hydrocortisone & 7 & 3.14 \\
\hline Others $^{*}$ & 54 & 24.21 \\
\hline Total $^{*}$ & 223 & 100 \\
\hline
\end{tabular}

*Others include furosemide, diazepam, quinine, Tetracycline (TTC) eye ointment, vitamin $A$, diclofenac injection, dexamethasone, cotrimoxazole, griseofulvin, maintenance fluid

Table 7: Most frequently co-administered drugs with crystalline penicillin in pediatrics ward, JUSH, January 1 to December 31, 2012

were the most co-administered drugs which represents 69(30.94\%). Salbutamol oral solution and puffs (aerosols) followed by 68 (34.49\%) and continued by intranasal oxygen and metronidazole oral suspension which were constitutes $35(15.7 \%)$ and 12 (5.30\%), respectively. Parenteral preparation of aminophylline and hydrocortisone were the least number of co-administered drugs that represents 8 (3.59\%) and $7(3.14 \%)$ respectively (Table 8$)$. With regard to drug interaction, only $2(1.1 \%)$ cases of concomitant use of gentamycine with crystalline Penicillin were reported. But the investigators were unable to verify if both drugs were administered in the same IV set.

\section{Discussion}

To date, there are no published studies conducted on evaluation of crystalline penicillin use in pediatrics population and hence it was not possible to compare the practice of this hospital with practices of other clinical settings. The findings were discussed in relation to the national STG of Ethiopia for General Hospitals and WHO Guidelines for the management of common illnesses in children in areas with limited resources.

The immunity status of pediatric population exposes them to various disease conditions majorly infectious in nature [23]. So, medicines are widely used in these groups of patients and hence there is a need to assess the rationality of drug use in these groups of patients. To improve the rationality of drug prescription, it is essential to have baseline information about the drug utilization pattern in this group of patients.

The demographic results of patients admitted at the pediatric wards studied shows that more numbers of males were admitted compared to their female counterparts. Similar studies also reported related findings. Study done in Nepal on Prescribing Pattern of antibiotics in Pediatric Hospital reported that the number of male patients was comparatively more than female patients [24]. Other Similar findings were also reported in a study done in Ethiopia [25].

Concerning indication for use of crystalline penicillin, in all the disease conditions where it was used, it was $100 \%$ as per the recommendation of the guidelines. The research findings showed that that severe pneumonia was the most common indication for crystalline penicillin use $114(62.29 \%)$, followed by pyogenic meningitis 38 (20.77\%) and generalized tetanus 31 (16.94\%). Similar results were reported from study done in Nepal where among all patients prescribed with antibiotics, pneumonia was the most common diagnosis. Pneumonia was the leading cause of hospital admission among infants, followed by meningitis. Benzyl penicillin (crystalline penicillin) was prescribed in highest percentage in pneumonia [24].

In this study there were $26(14.21 \%)$ patients treated with antibiotics before indication of crystalline penicillin. About 9 patients were diagnosed with pneumonia and treated by cotrimoxazole oral suspension. After some days this antibiotics was changed in to crystalline penicillin. This may be due to severity of the condition. This result fits with WHO guidelines recommendations for the management of common illnesses with limited resources to treat children with pneumonia as an outpatient. Cotrimoxazole $(4 \mathrm{mg} / \mathrm{kg}$ trimethoprim $/ 20$ $\mathrm{mg} / \mathrm{kg}$ sulfamethoxazole twice a day) for 3 days or amoxicillin $(25 \mathrm{mg} /$ $\mathrm{kg} 2$ times a day) for 3 days in non-HIV settings is recommended. In HIV settings, 5 days is recommended [26].

As most of the population in developing countries exist under conditions of poverty, inadequate medical care, poor sanitation and nutrition; bacterial infection account for much of the morbidity and mortality particularly in the pediatrics age group [27,28]. The widespread use of antimicrobials, whether appropriate or inappropriate, has driven the emergence and spread of resistant organisms. The association of resistance with the use of antibiotics has been documented in both inpatient and outpatient $[29,30]$ settings. Children can be protected from resistant bacteria through the judicious use of antimicrobial agents by their health care providers.

It has been noted through other previous studies undertaken in evaluating antibiotic use in hospitals that up to $50 \%$ of prescriptions can be inappropriate [31]. But without the appropriate use of antibiotics/ anti-infective, the ultimate objective of improving the quality of life of patients would be jeopardized.

In this study, the use of crystalline penicillin when evaluated with regard to dose and duration of therapy was found to be appropriate for the justification of use in 119 cases $(65.03 \%)$. They fulfill recommendation of STG of Ethiopia and WHO Guidelines for correct usage. The STG of Ethiopia recommended that for the treatment of pyogenic meningitis chloramphenicol, $50 \mathrm{mg} / \mathrm{kg}$ IV single dose followed by $100 \mathrm{mg} / \mathrm{kg} / 24$ hours divided in to four doses (Q 6 hourly)+crystalline penicillin, $50,000 \mathrm{IU} / \mathrm{kg}$ IV single dose followed by $250,000 \mathrm{IU} / \mathrm{kg} / 24$ hours IV divided in 8 doses (Q 3 hour). Duration of treatment depends on the etiology but in general course of treatment ranges between 10-15 days. For severe pneumonia benzyl penicillin, 50,000 units $/ \mathrm{kg} / 24 \mathrm{hrs} \mathrm{IM}$ or

\begin{tabular}{|c|c|c|}
\hline Criteria & $\begin{array}{c}\text { Expectation/ Threshold } \\
\text { No. (\%) }\end{array}$ & Actual performance No. (\%) \\
\hline Indication & $183(100)$ & $183(100)$ \\
\hline Dose & $174(95)$ & $149(81.42)$ \\
\hline Dose frequency & $174(95)$ & $183(100)$ \\
\hline Duration & $165(90)$ & $153(83.6)$ \\
\hline Drug interactions & $165(90)$ & $181(98.9)$ \\
\hline Contra-indications & $183(100)$ & $183(100)$ \\
\hline Outcome & $174(95)$ & $168(91.80)$ \\
\hline
\end{tabular}

Table 8: Summary of actual performance versus set criteria and thresholds fo crystalline penicillin use in pediatrics ward, JUSH, January 1 to December 31, 2012. 
IV QID for at least 3 days and Tetanus Immune Globulin (TIG), 500 3000 IU IM should be given+penicillin G Sodium Crystalline, 50,000 $\mathrm{IU} / \mathrm{kg} / 24 \mathrm{hrs}$ QID for ten days+chlorpromazine, $1.6 \mathrm{mg} / \mathrm{kg} / 24$ hours divided in to 4 doses IV/IM in the treatment of tetanus [22].

The causes of inappropriate crystalline penicillin use included incorrect dose of treatment as per the weight of the patient and inappropriate duration of therapy. In this research incorrect doses were used for all the observed cases i.e., severe pneumonia, pyogenic meningitis and Generalized Neonatal tetanus. In the current study, about 64 patients (34.97\%) were treated with inappropriate crystalline penicillin. The dose of crystalline penicillin in pediatric patient must be calculated as per to weight of the patient to minimize over dose or under dose. Obviously prescribing drugs without specifying the dose could lead to treatment ineffectiveness or ADRs. The recommended dose of crystalline penicillin according to STG of Ethiopia were 50,000 IU/kg IV single dose followed by $250,000 \mathrm{IU} / \mathrm{kg} / 24$ hours IV for the treatment of pyogenic meningitis, 50,000 units $/ \mathrm{kg} / 24 \mathrm{hrs}$ IM or IV QID for severe pneumonia and tetanus [22].

In the present study, the minimum duration of treatment was one day and 32 days was the maximum one. Different results were reported from study done in Chandigarh on Penicillin and gentamicin Therapy versus Amoxicillin/Clavulanate in Severe Hypoxemic Pneumonia which explains that minimum duration of IV therapy was 3 days and total 7 days [31]. This difference may be due to the study in Chandigarh was carried out on specific disease state which is severe pneumonia.

In this study, about 20 patients (10.93\%) were managed for more than 15 days which did not match with STG of Ethiopia and WHO guidelines that advice duration of treatment of pyogenic meningitis depends on the etiology but in general course of treatment ranges between 10-15 days, at least 3 days for severe pneumonia and ten days for tetanus [22]. WHO guidelines for the management of common illnesses with limited resources recommended that for meningitis to give treatment parentally for at least 5 days if the diagnosis is confirmed. Once the child has improved, oral chloramphenicol is recommended unless there is concern about oral absorption (e.g, in severely malnourished children or in those with diarrhea), where the full treatment should be given parentally. The total duration of treatment is 10 days. For severe pneumonia at least 3 days were recommended [21]. So, both guidelines recommended maximum of 15 days duration of therapy in the case of treatment pyogenic meningitis and tetanus. The probable reason for this deviation from the recommendation by the guideline might be because Ethiopia doesn't have STG for referral hospitals, physicians might be prescribing based on their experiences. This clearly indicates the need for some intervention to hamper the rampant over use of the drug.

According to Pediatric Community Pneumonia Guidelines Recommendations Treatment courses of 10 days have been best studied for CAP, although shorter courses may be just as effective, particularly for more mild disease managed on an outpatient basis. Infections caused by certain pathogens, notably CA-MRSA, may require longer treatment than those caused by S. pneumonia [32]. Short-course (3day) therapy has been studied in the developing world, but the clinical, laboratory, and radiographic description of these study patients is less definitive than in developed countries, and documentation of a bacterial pathogen is infrequent [33]. Although the total course of therapy is often 10 days, transition to oral therapy has been often used to allow discharge from an inpatient setting, providing decreased risks from intravenous administration of therapy and exposure to nosocomial pathogens [32].

Limiting the spectrum of activity of antimicrobials to that specifically required to treat the identified pathogen is preferred. Using the proper dosage of antimicrobial to be able to achieve a minimal effective concentration at the site of infection is important to decrease the development of resistance. Treatment for the shortest effective duration will minimize exposure of both pathogens and normal microbiota to antimicrobials, and minimize the selection for resistance [32].

In agreement with the STG of Ethiopia and WHO guidelines, the frequency of administration for crystalline penicillin in all the study patients (183) was similar. It was administered every four hours (Q 4 hours) for the management of all cases. This result related with the study done on an evaluation of Penicillin therapy in Acute Hematogenous osteomyelitis reported that the intervals between injections of penicillin sodium aqueous preparation were usually two or three hours [34]. This is an encouraging finding for containment of microbial resistance and emergence of ADR.

Perhaps the most obvious advantage of converting from IV to PO is that drug costs are decreased, as most PO medications are less expensive than their IV counterparts. Beyond saving on the actual cost of the medication, additional savings are realized by eliminating IV sets and pumps and reducing nursing and pharmacy personnel time spent on IV-related activities. Several studies published in the last decade document the cost savings associated with successful IV to PO conversion programs [35].

From a clinical perspective, patients who are converted to PO earlier in treatment and recovery may have an easier time ambulating, as they are not connected to IV poles, and switching to PO lessens the risk for infusion-related adverse events that are associated with their IV equivalents. Expeditious removal of IV catheter lines during a patient's hospital stay reduces the risk of developing secondary infections associated with IV lines. Furthermore, as IV to PO switches decrease the average patient's length of stay in a hospital, the overall risk of developing hospital-acquired infections is reduced. In many cases, PO drugs are more easily acquired and handled, and are more convenient for the pharmacy because they take up less space and are easier to store in larger quantities than IV medications [35].

In the present study, nearly half of the pediatric patients $88(48.09 \%)$ switched to other medication especially oral antibiotics. Out of this, 84 cases had assessment of severe pneumonia and 4 cases were due to pyogenic meningitis. Most of the patients were discharged with oral amoxicillin and cotrimoxazole. In $86(47 \%)$ patients crystalline penicillin was converted to PO medication. An intravenous (IV) to oral conversion program can lower drug costs for an institution and its patients and is a wise and beneficial decision is done with due care. Numerous studies have documented clinical efficacy, fewer complications, shorter hospital stays, and cost savings by converting patients from IV to oral therapy $[35,36]$. The most common medications targeted for a program of this type are antimicrobials, because these agents often account for $20 \%-40 \%$ of an institution's drug budget [36]

Patients diagnosed with severe pneumonia were eligible for conversion IV to PO medication unless and other wise there were patients with non functioning GI tract and presence of bowel abnormalities and patients not showing signs and symptoms of clinical improvement. Patients are eligible for discharge when they have documented overall clinical improvement, including level of activity, appetite, and decreased fever for at least 12-24 hours and if 
they only demonstrate stable and/or baseline mental status. Patients are not eligible for discharge if they have substantially increased work of breathing or sustained tachypnea or tachycardia. Patients should have documentation that they can tolerate their home anti-infective regimen, whether oral or intravenous and home oxygen regimen, if applicable, before hospital discharge (54).

The research findings indicated that no case contra-indications was reported in the administration of crystalline penicillin among the study population and this is line with the guidelines and very promising and acceptable when viewed against the set threshold.

Now a day, there is a tendency to consider potentially serious drugdrug interactions as an indicator for appropriateness of prescribing practice. Because of these interactions have both clinical and economic implications [37]. In this study, some cases, 2(1.1\%), were managed by the concurrent administration of gentamicin with crystalline penicillin. Although the severity associated with the interaction between amino glycoside and penicillin groups of antibiotics is mild, it is prescribed together sometimes. This may be because of the fact that these two drugs are commonly prescribed together for their synergistic effect. However, the chemical inactivation of gentamicin by $\beta$-lactam antibiotics will reduce the effectiveness of gentamicin. Therefore, prescribers must be aware that there may be a need to monitor the serum level of gentamycin and dose adjustment (additional dose of gentamicin) may be required. Additionally, the concomitant administration of amino glycosides and penicillin through intravenous system should also be avoided. Prescribers should give due emphasis during prescribing of drugs which are known for their drug-drug interaction property.

Among the medications co-administered with crystalline penicillin, paracetamol suppository and oral solutions were the most co-administered drugs which represent 69(30.94\%), followed by Salbutamol oral solution and puffs (aerosols) 68(34.49\%). This may be for the purpose of treating fever and wheezing or shortness of breath associated with severe pneumonia.

In this study though less than the set threshold, clinical improvement (better outcome) was clearly documented for 168 patients $(91.80 \%)$, which were identified from conversion of crystalline penicillin to oral antibiotics and discharge summary. since no any feedback was written on the patient's medical records for 12 cases (6.56\%), even the finding would have been higher and even around or more than the threshold set.

\section{Conclusions}

In conclusion, crystalline penicillin utilization pattern in pediatric ward of Jimma University Specialized Hospital fully adhered to the STG of Ethiopia for General Hospitals and WHO Guideline for the majority of the parameters with regard to indication to use, contraindications, drug interactions and dose frequency and met the thresholds set for most of the criteria. But, dose, duration and outcome were not according to the abovementioned guidelines and failed to met the thresholds set for each specific criteria.

The majority of inappropriateness of crystalline penicillin use was seen with dose and duration of therapy. The dose of crystalline penicillin in most pediatric patient was not calculated as per the weight of the patient to minimize over or under dosing. Adherence to STG is important in the provision of rational medicine use. But the present study showed that prescriber's adherence to the guidelines is low which needs additional work to be done.

According to data generated by this DUE, a combination of physician education programs and feedback control systems directed toward rational crystalline penicillin use is suggested for proper medical treatment.

\section{Acknowledgements}

The authors are very grateful to all the data collectors and all administrative bodies at Jimma University Specialized Hospital (JUSH) who participated or assisted in the data collection process. The authors also would like to extend their thanks to the Student Research Project of Jimma University for sponsoring the study

\section{Conflict of Interest}

The authors declare that they did not have any conflict of interest.

\section{References}

1. Phillips MS, Gayman JE, Todd MW (1996) ASHP guidelines on medication-use evaluation. American Society of Health-system Pharmacists. Am J Health Syst Pharm 53: 1953-1955.

2. SHPA Committee (2004) SHPA Standard of practice for drug use evaluation in Australian Hospital. J Pharm Pract Res 34: 220-223.

3. The Academy of Managed Care Pharmacy's, concepts in managed care pharmacy (2008) Drug use evaluation. Alexandria.

4. WHO (2003) Drug and therapeutic committee-A practical guide to drug use evaluation. Drug use evaluation (Drug utilization review), 155, Geneva Switzerland.

5. WHO (1998) Promoting appropriate Drug use in Missionary health Facilities in Cameroon-EDM Research Series No. 028. Geneva, Switzerland.

6. Moore T, Bykov A, Savelli T, Zagorski A (1997) Guidelines for Implementing Drug Utilization Review Programs in Hospitals. Rational Pharmaceutica Management Project-Russia, Management Sciences for Health, Arlington, Moscow, Russia.

7. Moellering RC (2000) Principles of anti-infective therapy. In: Mandell GL, Bennett JE, Dolin R, (eds): Mandell, Douglas, Bennett's Principles and Practice of Infectious Diseases, Churchill Livingstone, United States: 223-235.

8. Teng CL, Shajahan Y, Khoo EM, Nurjahan I, Leong KC, et al. (2001) The management of upper respiratory tract infections. Med J Malaysia 56: 260-266.

9. Mlynarczyk G, Mlynarczyk A, Jeljaszewicz J (2001) Epidemiological aspects of antibiotic resistance in respiratory pathogens. Int $\mathrm{J}$ Antimicrob Agents 18 : 497-502.

10. Roncevic N, Popadic J, Stojadinovic A (2002) Treatment of acute infections of the lower respiratory tract in children. Med Pregl 55: 299-304.

11. WHO (2002) Promoting Rational Use of Medicines: Core Components. WHO Policy Perspectives on Medicines, Geneva, Switzerland.

12. Currò V, Soavi N, Grimaldi V, Bembo V, Procaccini M, et al. (1992) The catarrhal child. Pediatr Med Chir 14: 183-191.

13. West JV (2002) Acute upper airway infections. Br Med Bull 61: 215-230

14. Hux JE, Melady MP, DeBoer D (1999) Confidential prescriber feedback and education to improve antibiotic use in primary care: a controlled trial. CMAJ 161: 388-392.

15. World Bank (1994) The Importance Of Pharmaceutical And Essential Drug Programmes: Better Health In Africa, Experience And Lessons Learned .World Bank Report, World Bank, Washington DC, USA.

16. Hecker MT, Aron DC, Patel NP, Lehmann MK, Donskey CJ (2003) Unnecessary use of antimicrobials in hospitalized patients: current patterns of misuse with an emphasis on the antianaerobic spectrum of activity. Arch Intern Med 163 972-978.

17. World Health Organization (2010) WHO model formulary for children 2010 Geneva, Switzerland.

18. Lee H, Jung D, Yeom JS, Son JS, Jung SI, et al. (2009) Evaluation of ceftriaxone utilization at multicenter study. Korean J Intern Med 24: 374-380.

19. Seppälä H, Klaukka T, Vuopio-Varkila J, Muotiala A, Helenius H, et al (1997) The effect of changes in the consumption of macrolide antibiotics on erythromycin resistance in group A streptococci in Finland. Finnish Study Group for Antimicrobial Resistance. N Engl J Med 337: 441-446. 
Citation: Siraj J, Ahmed SM (2013) Evaluation of Crystalline Penicillin Use in Pediatrics Ward of Jimma University Specialized Hospital, South West Ethiopia. Clin Exp Pharmacol 3: 135. doi:10.4172/2161-1459.1000135

20. Jimma University (2013) Jimma University Specialized Hospital (JUSH).

21. WHO (2005) Pocket book of hospital care for children Guidelines for the management of common illnesses with limited resources. Geneva, Switzerland.

22. Food, Medicine and Health Care Administration and Control Authority (FMHACA), of Ethiopia (2010) Standard Treatment Guideline for General Hospitals. (2ndedn), Addis Ababa, Ethiopia.

23. Steinberg I (2009) Pediatric infectious disease. In: Applied Therapeutics the clinical use of drugs, (9thedn), Lippincott Williams \& Wilkins, New York, USA.

24. Palikhe N (2004) Prescribing pattern of antibiotics in paediatric hospital of Kathmandu valley. Kathmandu Univ Med J (KUMJ) 2: 6-12.

25. Mengistu A (2005) Patterns of Drug Utilization In Inpatient Departments, Jimma Hospital South West Ethiopia. Ethiop J Health Sci $15: 139-145$.

26. Abebe FA, Berhe DF, Berhe AH, Hishe HZ, Akaleweld MA (2012) Drug use evaluation of Ceftriaxone: The Case of Ayder Referral Hospital, Mekelle, Ethiopia. Int J Pharm Sci Res 3: 2191-2195.

27. Walsh JA, Warren KS (1979) Selective primary health care: an interim strategy for disease control in developing countries. N Engl J Med 301: 967-974.

28. Riley L, Carad E, Graltn H (1983) The status of research on acute respiratory infection in children in Papua New Guinea. Paediat Res 17: 1041-1043.

29. McGowan JE (1983) Antimicrobial resistance in hospital organisms and its relation to antibiotic use. Rev Infect Dis 5: 1033-1048.
30. Reichler MR, Allphin AA, Breiman RF, Schreiber JR, Arnold JE, et al. (1992) The spread of multiply resistant Streptococcus pneumoniae at a day care center in Ohio. J Infect Dis 166: 1346-1353.

31. Gould IM, Jappy B (1996) Trends in hospital antibiotic prescribing afte introduction of an antibiotic policy. J Antimicrob Chemother 38: 895-904.

32. Bradley JS, Byington CL Shah SS, Alverson B, Carter ER et al. (2011) The Management of Community-Acquired Pneumonia in Infants and Children Older Than 3 Months of Age: Clinical Practice Guidelines by the Pediatric Infectious Diseases Society and the Infectious Diseases Society of America. Clin Infect Dis 53: e25-e76.

33. Haider BA, Saeed MA, Bhutta ZA (2008) Short-course versus long-course antibiotic therapy for non-severe community-acquired pneumonia in children aged 2 months to 59 months. Cochrane Database Syst Rev: CD005976.

34. Altemeier WA, Wadsworth CL (1948) An evaluation of penicillin therapy in acute hematogenous osteomyelitis. J Bone Joint Surg Am 30A: 657-673.

35. University of Illinois (2013) Chicago College of Pharmacy Drug Information Group Web site. FAQs.

36. Williams D, Kelly A, Feely J (2000) Drug interactions avoided-a useful indicato of good prescribing practice. Br J Clin Pharmacol 49: 369-372.

37. Zamin MT, Pitre MM, Conly JM (1997) Development of an intravenous-to-ora route conversion program for antimicrobial therapy at a Canadian tertiary care health facility. Ann Pharmacother 31: 564-570. 